\title{
"Se parar, parou": categorização do \\ morrer em uma unidade de terapia intensiva da cidade do Rio de Janeiro
}

I ${ }^{1}$ Nathalia Ramos da Silva, ${ }^{2}$ Rachel Aisengart Menezes |

\begin{abstract}
A unidade de terapia intensiva foi criada para atender enfermos muito graves, com risco de vida. Para tanto, conta com assistência médica e de enfermagem ininterruptas, com equipamentos específicos, recursos humanos especializados e acesso a aparelhagem sofisticada, destinada a diagnóstico e terapêutica, para manutenção da vida. Este artigo apresenta uma reflexão em torno das possibilidades de processos do morrer em uma unidade de tratamento intensivo, com base em pesquisa etnográfica em hospital público universitário da cidade do Rio de Janeiro. Apesar do contato frequente com o processo do morrer, em certas situações, alguns intensivistas demonstram tensão e/ou dificuldade na aceitação da morte, especialmente em situações de "morte inesperada". Neste tipo de situação, alguns profissionais expressam sentimentos, especialmente aqueles com mais tempo de contato com o doente. Já na "morte esperada", os profissionais esperam que ela ocorra e, assim há menor mobilização de sentimentos. Como a rotina da unidade não deve ser perturbada, estratégias são construídas e acionadas para lidar com essas situações. O estudo evidenciou o recurso ao humor, quando eufemismos e brincadeiras emergem, para aliviar a tensão que porventura se instale no ambiente da unidade de terapia intensiva, setor em que a morte é uma presença cotidiana.
\end{abstract}

> Key words: terapia intensiva; emoções; vida/morte; óbito; parada cardiorrespiratória.

\author{
1 Instituto de Estudos em \\ Saúde Coletiva, Universidade \\ Federal do Rio de Janeiro. Rio \\ de Janeiro-RJ, Brasil. Endereço \\ eletrônico: nathramos@ \\ hotmail.com \\ 2 Instituto de Estudos em \\ Saúde Coletiva, Universidade \\ Federal do Rio de Janeiro. Rio \\ de Janeiro-RJ, Brasil. Endereço \\ eletrônico: raisengartm@terra. \\ com.br
} Recebido em: 22/05/2014
Aprovado em: 10/12/2014 


\section{Introdução}

As primeiras unidades de cuidados intensivos ${ }^{1}$ foram criadas a partir do reconhecimento, por parte da equipe de enfermagem, da importância de controle e vigilância sobre doentes graves, em situação de risco de vida. Para tanto, eles passaram a ser agrupados em áreas específicas do hospital. Assim, os enfermeiros poderiam se certificar de que os pacientes mais graves receberiam mais atenção, quando alocados próximos ao posto de enfermagem.

Em 1926, foi criada a primeira unidade intensiva em Baltimore, Estados Unidos, pelo neurocirurgiāo Walter Dandy, com três leitos pós-operatórios de neurocirurgia, no Hospital John Hopkins, segundo a Society of Critical Care. ${ }^{2}$ Este serviço foi o preconizador do modelo inicial de unidade de tratamento intensivo. Em 1947 e 1948, em decorrência de uma epidemia de poliomielite, que ocorreu tanto na Europa e quanto nos Estados Unidos, os doentes permaneciam no mesmo ambiente para monitorização, na busca pela manutenção da vida. No mesmo período foram desenvolvidos os ventiladores mecânicos, ${ }^{3}$ para insuficiência respiratória.

$\mathrm{Na}$ Segunda Guerra Mundial, os pacientes em pós-operatório eram agrupados em salas de recuperação, a fim de garantir um atendimento eficaz. Em 1958, aproximadamente 25\% dos hospitais norte-americanos com mais de 300 leitos contava com uma UTI. Os benefícios deste setor resultaram em sua disseminação, sobretudo a partir dos anos $1960 .{ }^{4}$ No Brasil, essa modalidade de serviço surgiu nessa década, em hospitais de grande porte do Sul e Sudeste do país (MENEZES, 2006). Segundo o Ministério da Saúde brasileiro (1998), as UTIs são unidades hospitalares destinadas ao atendimento de enfermos graves ou de risco, ${ }^{5}$ que dispõem de assistência médica e de enfermagem ininterruptas, com equipamentos específicos e recursos humanos especializados, além de acesso a tecnologias para diagnóstico e terapêutica.

Essa unidade representa a preocupação moderna com o controle de doenças. Sua meta consiste na cura, no prolongamento e/ou na manutenção da vida. Desde seu surgimento, questionamentos têm se apresentado sobre as consequências de uma internação no setor e, também, acerca das condições de trabalho da equipe (MENEZES, 2013). A morte é uma presença constante na UTI e os profissionais estão em contato rotineiro com o processo do morrer. Por vezes, os recursos 
técnicos, o saber e a competência do intensivista são limitados, diante do avanço

da enfermidade, especialmente quando a cura não é possível, com o diagnóstico de "fora de possibilidades terapêuticas de cura".

A UTI é um local exemplar de um modelo de gestão do processo do morrer, denominado por Ariès (2012) como "morte moderna", caracterizado pela medicalização do morrer. Lofland (1978) apresenta seis características do modelo de "morte moderna": alta tecnologia da medicina, detecção prévia da doença, definição complexa da morte, alta prevalência de doença crônica, baixa incidência de doenças fatais e intervenção ativa no processo do morrer. Segundo Ariès (2012, p. 84), este modelo implica excessos de poder da equipe médica, que tende a perceber o doente de modo fragmentado e objetificado. A prioridade da assistência é concedida à extensão da vida, o que é apontado em estudos sobre o hospital e a UTI, publicados a partir dos anos 1960 (GLASER; STRAUSS, 1965; SUDNOW, 1967; SEYMOUR, 2001; ARIÈS, 2012; MENEZES, 2000 e 2006).

Neste artigo, apresentamos uma reflexão sobre a categorização da morte em uma UTI, com base em pesquisa etnográfica realizada em hospital público universitário da cidade do Rio de Janeiro. ${ }^{7}$ A observação foi iniciada em fevereiro de 2013, após autorização das chefias e da direção, e compreendeu o período de quatro meses, totalizando 356 horas. A pesquisadora que desenvolveu a observação esteve presente em diferentes períodos do dia, e também em plantões noturnos, para apreender o ritmo de trabalho.

\section{A UTI observada}

A Unidade de Terapia Intensiva em que foi realizada a pesquisa está inserida no Hospital Universitário Gaffrée e Guinle (HUGG), da Universidade Federal do Estado do Rio de Janeiro (UNIRIO). Situa-se na zona norte da cidade do Rio de Janeiro. Atualmente, o hospital possui cerca de 200 leitos para internação e não oferece atendimento de emergência, apenas ambulatorial.

A pesquisadora que empreendeu a observação é fisioterapeuta e atua nessa unidade. Portanto, na investigação teve dupla identidade: integrante da equipe e pesquisadora. Como profissional de saúde da unidade, sempre usou jaleco, assim como todos os membros do setor. Uma das premissas das ciências sociais é a necessidade de uma distância mínima que garanta ao investigador condições 
de objetividade em seu trabalho. $\mathrm{O}$ pesquisador deve observar a realidade com "olhos imparciais", evitar envolvimentos que possam deformar ou distorcer seus julgamentos e conclusóes. Nesse sentido, o estudo do familiar oferece vantagens em termos de possibilidades de rever e enriquecer os resultados da pesquisa. $\mathrm{O}$ processo de estranhar o familiar torna-se possível quando somos capazes de confrontar intelectualmente, e mesmo emocionalmente, diferentes versões e interpretações existentes a respeito de fatos e situações (VELHO, 1978). A dupla identidade da pesquisadora demandou maior capacidade de reflexão e autocrítica, tanto no período de observação quanto na análise dos dados e redação do estudo. Nesse tipo de trabalho de campo, trata-se de transformar o familiar em exótico (DAMATTA, 1978). O desafio consistiu em despir a roupagem de fisioterapeuta, para estranhar regras já conhecidas.

A observação teve início em um período em que a UTI encontrava-se em obras, de modo que as primeiras observações foram realizadas em um espaço reduzido, com número menor de leitos em relação ao habitual - antes com oito e na etapa com obras apenas dois -, uma vez que profissionais e pacientes foram alocados em uma enfermaria. A permanência neste local foi de sete meses. Por se tratar de ambiente restrito, com poucos recursos para funcionamento de uma UTI, comportava dois doentes. Com o término da obra, em março de 2013, a equipe retornou a um ambiente reformado, com paredes pintadas de verde claro, com novos móveis, bege e azul.

Para entrar no setor é preciso passar por uma porta "vai e vem" de plástico, que dá acesso a um corredor, no qual há um banheiro para familiares de pacientes; um espaço para armazenamento de material; e armários individuais, para funcionários. Ao lado há uma porta, que dá acesso à UTI. Ao entrar neste espaço, é possível observar frontalmente o posto de enfermagem, no centro do ambiente, com formato retangular. Ele é dividido em duas partes: uma com bancadas, utilizada pelos profissionais para escrever nos prontuários. $\mathrm{O}$ outro espaço é destinado ao preparo de medicações, isolada por uma divisória com janelas de vidro e duas portas pequenas "vai e vem" de madeira, para evitar a circulação no local. O posto está em nível superior do restante do ambiente (um degrau acima), para que seja possível a visão dos leitos. Há cinco leitos do lado esquerdo e sete do direito, mas nem todos são ativos. À época da pesquisa, apenas oito eram utilizados: quatro do lado esquerdo, sendo um para isolamento 
respiratório, e quatro à direita. Trata-se de uma estrutura semelhante à do panóptico de Bentham (FOUCAULT, 2004): uma organização com máxima visibilidade do ponto central, possibilitando controle e vigilância permanentes.

Os leitos estão dispostos com as cabeceiras encostadas nas paredes e os pés voltados para o posto de enfermagem, separados por cortinas presas ao teto. Em cada cabeceira há uma janela (que não abre) e grande quantidade de aparelhos. ${ }^{8}$ Ao lado, uma mesa e uma cesta plástica, com materiais de uso cotidiano, como sondas, gazes e luvas.

Atrás do posto de enfermagem, há uma sala com janelas de vidro, denominada pelos profissionais como "aquário", com uma mesa, computador e impressora, sofás, um negatoscópio e e um quadro de cortiça. Este espaço é usado pelos médicos para discussão dos casos, juntamente com as equipes de fisioterapia e enfermagem.

Ao entrar na UTI, algumas características do ambiente se destacam: a baixa temperatura ambiente, mantida por aparelhagem de ar condicionado central; iluminação constante, com lâmpadas fluorescentes; janelas sempre fechadas, cobertas por filme; muitos ruídos, de conversas entre os profissionais, dos alarmes dos aparelhos, do telefone, celulares e do rádio, ligado no posto de enfermagem. Os odores são perceptíveis e variáveis, causados pela mistura de cheiros: materiais de limpeza, secreções e medicações. Há também muitos dispensers de álcool gel nas paredes do setor.

\section{Rotina}

Na UTI observada, circulam muitos profissionais: médicos, enfermeiros, técnicos de enfermagem, fisioterapeutas, nutricionistas, fonoaudiólogos, dentista, residentes, acadêmicos, funcionários da limpeza e do setor administrativo. ${ }^{10}$ Cada plantão, diurno ou noturno, conta com um médico plantonista, um fisioterapeuta, dois enfermeiros, cinco técnicos de enfermagem e um funcionário da limpeza. O plantão diurno conta ainda com dois residentes de fisioterapia, acadêmicos de medicina (em geral quatro) e enfermagem (dois), o médico, o fisioterapeuta e o enfermeiro da rotina, dois funcionários administrativos, um técnico de enfermagem diarista, além de cirurgiōes e nefrologistas, ${ }^{11}$ responsáveis pela avaliação de doentes internados. Usualmente, os plantões diurnos são mais movimentados que os noturnos e os finais de semana. A dentista tem dias marcados de trabalho. Os nutricionistas 
e fonoaudiólogos não pertencem exclusivamente à equipe da UTI, atendem em todo o hospital e só estão presentes no período diurno.

Segundo pesquisa de Menezes (2006), há uma tendência, da parte de cada categoria profissional, a se relacionar com seus pares. Apesar da existência de diferenças e tensões entre os grupos que trabalham na UTI, há uma identidade profissional singular, que perpassa todos os envolvidos - a de intensivista. Segundo a Associação de Medicina Intensiva Brasileira, ${ }^{12}$ "intensivista é o nome dado ao profissional dedicado ao atendimento do paciente internado em unidades emergenciais, tais como prontos-socorros e UTIs".

A rotina diária se inicia às sete horas, com a "passagem de plantão" das equipes de enfermagem, medicina e fisioterapia, quando informes detalhados são transmitidos sobre os pacientes internados. O plantão termina às 19 horas com o mesmo processo, para a equipe que chega para "render" a que está de plantão. Pela manhã, enfermeiros e técnicos dão banho nos doentes, geralmente nos leitos. Simultaneamente, médicos avaliam os pacientes, ajustam as medicações e determinam quais podem receber alta para enfermarias e quais serão internados. A equipe de fisioterapia efetua ajustes na ventilação mecânica e se dedica à atividade motora. As equipes de nutrição, fonoaudiologia, cirurgia e nefrologia avaliam os enfermos. À tarde, as equipes aguardam as internações que procedem do centro cirúrgico e transferem os pacientes em condiçôes para enfermarias. Os funcionários administrativos, o médico, o fisioterapeuta e o enfermeiro da rotina não permanecem no setor, pois seu horário de trabalho é concluído no almoço. Assim, nesse período há menor circulação no setor. Quando não há intercorrências, os intensivistas conversam, assistem à televisão, lancham.

Às 14 horas ocorre a visita de familiares, com duração de uma hora, quando é autorizada a entrada de uma pessoa por vez. Todos os visitantes são orientados a lavar as mãos antes e após o contato com o doente. Há também um horário de visita às 19h30min, com duração de 30 minutos.

Ao se aproximar do término do plantão, a equipe de enfermagem se organiza para "passar o plantão". Às 19 horas ocorre nova troca de plantão e a rotina recomeça. A equipe intensivista trabalha de forma ininterrupta, na busca pelo total controle dos pacientes. Quando há qualquer alteração nos parâmetros ou funçôes vitais dos doentes, os intensivistas atuam para controlar a intercorrência. 


\section{"Se parar parou": "SPP"}

$\mathrm{Na}$ rotina da unidade observada, ${ }^{13}$ há uma diferença entre óbito e parada cardiorrespiratória (PCR). Os termos se distinguem pela decisão (ou não) de reanimação. Quando um paciente recebe o diagnóstico de "fora de possibilidades terapêuticas de cura", a equipe avalia que a prioridade não mais reside no "investimento" e/ou uso de recursos para manutenção de sua vida. A escolha então recai sobre não tratar infecções que surjam. A equipe médica comunica que "se o paciente parar, parou" (SPP). No prontuário consta a orientação da conduta de "conforto", o que significa não realizar qualquer procedimento com a meta de cura. ${ }^{14}$ No caso de parada cardiorrespiratória, a ordem é não efetuar manobras de ressuscitação. Assim é definido o óbito.

Em geral, o responsável pela decisão é o médico da rotina. $\mathrm{O}$ doente e sua família não participam da escolha. Todos os profissionais da UTI tendem a acatar a indicação, ainda que alguns não concordem, pois a palavra final é do médico. A discordância pode ser observada quando ocorre uma parada cardíaca de paciente diagnosticado como "fora de possibilidades terapêuticas de cura". Por vezes, alguns intensivistas buscam a ressuscitação. Uma reportagem do jornal Folha de São Paulo descreveu um fenômeno recorrente em UTIs: em face de uma parada cardiorrespiratória, o médico plantonista empreende manobras de reanimação, inclusive em pacientes com a recomendação de "conforto". O lema que rege a atitude é a frase: “no meu plantão, não!”. Esta situação evidencia a afirmativa de Herzlich (1993, p. 7): "para o médico e para o hospital a morte é, antes de tudo, um fracasso". Consequentemente, tê-la sob sua responsabilidade não é mais do que assumir um empreendimento condenado ao insucesso. Ainda de acordo com a autora, para que o trabalho do médico possa se realizar, é preciso que a morte encontre seu lugar. Portanto, faz-se necessário retirar o caráter espetacular de crise que o término da vida traz, alterando as regras habituais (HERZLICH, 1993, p. 7).

A discussão em torno de uma "boa morte" na UTI é recorrente. Para os intensivistas, o "conforto" ao paciente é fornecido pela intubação orotraqueal, pela ventilação mecânica e uso de sedativos. Tal condição se opõe ao que é priorizado na assistência em Cuidados Paliativos: manutenção da autonomia do paciente, controle da dor e dos sintomas, de preferência sem intervençôes invasivas. O discurso sobre a produção de uma "boa morte" se centra na 
consciência da manutenção da identidade individual e na aceitação do processo do morrer. Contudo, a implementação, na prática, do modelo paliativista em UTI é complexa. Quando ocorre uma morte na UTI, geralmente é marcada pela vulnerabilidade e extrema dependência física do doente. Tal quadro resulta da gravidade de sua condição clínica, por vezes em decorrência da indução de coma, pela ação de drogas para alívio dos sintomas e do desconforto produzido pela terapia intensiva (SEYMOUR, 2001, p. 128).

O ideal na assistência paliativa é que a morte ocorra em casa, com controle dos sintomas, na companhia da família. O aspecto central é o diálogo entre os atores sociais envolvidos no processo do morrer: uma vez explicados os limites da ação do médico e dos desejos do doente, é possível a deliberação sobre o período de vida ainda restante, a escolha de procedimentos e a despedida das pessoas de suas relações, com o suporte da equipe multidisciplinar. A tomada de decisōes deste indivíduo depende de três requisitos: o conhecimento do avanço da doença e da proximidade da morte, por comunicação da equipe de saúde; a expressão dos desejos e sentimentos do paciente para as pessoas de sua relação e, finalmente, a escuta e atuação dos que cuidam do doente. O primeiro aspecto desse novo modelo é a consciência do indivíduo da proximidade de sua morte. De acordo com o ideário dos cuidados paliativos, os sentimentos face à finitude devem ser expressos (MENEZES, 2004).

A "boa morte" significa um processo em que o doente terminal, a família e a equipe profissional de saúde aceitam a morte que se aproxima e participam da tomada de decisōes compartilhada. Acima de tudo, esta maneira de morrer é dito ser digna e pacífica. Porém, ela só pode ocorrer se o enfermo, a família e os profissionais concordam com as medidas pouco antes da morte (PETERSEN; WADDELL, 1999, p. 170). Na UTI não é possível a ocorrência da morte de acordo com este modelo. Por vezes, o paciente está inconsciente e seus familiares não participam da tomada de decisóes, que se restringe aos intensivistas, sobretudo ao médico. Neste setor, o conforto é oferecido aos membros da equipe, uma vez que, para o alívio dos profissionais, por vezes decide-se entubar o enfermo e conectá-lo ao aparelho de ventilação artificial. A enfermagem usualmente apoia este tipo de intervenção, por considerar a meta de "menor sofrimento do paciente".

Segundo Seymour (2001, p. 152), a percepção do significado da tecnologia determina a construção de distintas representaçôes da "boa morte" em UTI. A 
partir de entrevistas com familiares de internados neste setor, a autora afirma que

a percepção do "morrer bem" depende das circunstâncias nas quais o paciente foi atendido, do uso da tecnologia pela equipe, bem como da aprovação, pela família, da intervenção médica.

A definição do paciente como "conforto" pode conduzir à manifestação de diferentes tipos de emoção dos profissionais de saúde. Por vezes, quando o médico da rotina informa à equipe que o paciente é "fora de possibilidades terapêuticas de cura”, alguns médicos plantonistas suspendem certas medicações e não atentam para analgesia e sedação do doente. Este aspecto é valorizado pela equipe de enfermagem, pois durante a execução da higiene e de curativos, os pacientes podem expressar desconforto. Afinal, são os profissionais da enfermagem que mantêm contato mais próximo e contínuo com os doentes. Por vezes, alguns enfermeiros não aceitam o diagnóstico e a conduta médica, o que provoca tensão na equipe. Para eles, o essencial é que o paciente não sofra, não sinta dor, seja ele "viável" ou não. Este dado foi também foi relatado por Seymour (2001, p. 63), em sua investigação em UTIs inglesas. ${ }^{16}$

A comunicação da equipe médica aos demais profissionais é necessária, pois quem monitora os doentes é a enfermagem. Esses profissionais informam ao médico uma parada cardíaca ou qualquer intercorrência. Entretanto, quando o enfermo é considerado "viável", recebe as formas possíveis de tratamento e, em caso de parada cardíaca, é prontamente reanimado. Assim é definida a PCR. Neste caso, os intensivistas realizam todas as condutas, para evitar a morte do doente, o que pode alcançar até uma hora de reanimação.

A PCR foi descrita por um professor de cardiologia (VINCENT, 1991) como um evento dramático, sem dignidade, mal compreendido e de resultado incerto (MEERABEAU; PAGE, 1998, p. 296). Durante uma PCR, pouco é expresso pelos profissionais, principalmente quando se trata de interromper os procedimentos. Via de regra, na unidade observada, apenas uma palavra é utilizada: “chega!”. Após esta afirmativa, os intensivistas olham para o monitor, para se certificarem de que o paciente efetivamente morreu. A partir de então, são iniciados os preparativos pósmorte. Porém, quando o doente "volta", usualmente não há comentários, apenas sorrisos, gestos e trocas de olhares com expressão de satisfação.

A principal diferença entre os dois termos - óbito e parada - concerne à expectativa dos profissionais e ao controle. No óbito, a equipe espera que ocorra 
a morte, de modo que não há reação. No segundo caso, ela é evitada ao máximo, pelo uso de aparelhagem e de medicamentos. Quando o doente morre, a equipe manifesta surpresa. Neste tipo de situação, é possível observar a emergência de expressão emocional dos intensivistas. Assim, se o enfermo é categorizado como FPTC, a morte é esperada, pois não se trata de uma "parada”, mas de um óbito.

Em certa ocasião, enquanto conversava com técnicos de enfermagem, a pesquisadora olhou para o monitor de um paciente FPTC e percebeu que a frequência cardíaca era zero. Ela se dirigiu então ao técnico: "acho que ele parou". O profissional foi até o leito, ajeitou os eletrodos de monitorização cardíaca, procurou o pulso e constatou ausência de batimentos. $\mathrm{O}$ outro técnico foi ao “aquário" comunicar à médica de plantão que o paciente havia "parado". O técnico retornou, dirigiu-se ao leito, fechou a cortina e disse: "Ela (a médica) pediu para esperar um pouco, pois está terminando de passar os casos (dos doentes) com os acadêmicos (de medicina)". Este episódio evidencia que a ocorrência de um óbito não acarreta alteração na atitude do médico. Não é preciso interromper a rotina do setor. Após a constatação de um falecimento, faz-se necessário o preparo do corpo pela enfermagem e a comunicação à família. A seguir, o médico deve decidir qual será o paciente a ocupar o leito. Importante ressaltar que a escolha para internação no setor segue uma classificação referente à viabilidade do enfermo. Ao surgir uma vaga, o médico é encarregado de avaliar o estado dos pacientes, para selecionar qual será transferido. Geralmente a preferência recai sobre doentes em pós-operatório, ou para enfermo "viável” e jovem.

Quando um óbito ocorre no setor, cada profissional tem uma função. O médico, ao confirmar o evento, anota o horário da parada cardíaca e comunica à enfermagem. $\mathrm{O}$ atestado de óbito deve ser preenchido pelo médico, e cabe à enfermeira entregá-lo aos familiares. Os técnicos de enfermagem preparam o corpo e, a seguir, se comunicam com o profissional da capela.

Nesse momento, cada profissional reage diversamente: alguns demonstram sentimentos, enquanto outros não alteram sua expressão e rotina de trabalho. A expressão de sentimentos varia de acordo com o contato do profissional com o doente. Assim, se ele for internado em determinado plantão e morrer com os mesmos profissionais que o internaram, pode haver mobilização. Para a equipe observada, há duas situações que usualmente são mais mobilizadoras: quando o paciente é jovem e quando a morte não é esperada. 
Durante o período de observação, ocorreram algumas mortes de figuras públicas. Diferentes formas de expressão de sentimentos ocorreram, relativamente em dois casos. Praticamente no mesmo dia, dois homens morreram: o presidente venezuelano, Hugo Chavez, e o cantor da banda Charlie Brown Jr., o Chorão. $\mathrm{O}$ primeiro faleceu em decorrência de um câncer na região pélvica, aos 58 anos. $\mathrm{O}$ segundo aos 42 anos, por overdose de cocaína. Surgiram então variados comentários na UTI observada, sobretudo referentes à morte do cantor, tão jovem. Ninguém esperava que ele fosse morrer, apesar do uso de drogas. "Foi uma surpresa!”, disse uma enfermeira, acerca do falecimento do artista. Já em relação à morte de Chavez, todos consideraram tratar-se de uma "morte esperada", pois ele tinha um câncer.

Este caso evidencia a diferença entre uma "morte inesperada" e "esperada", para a equipe intensivista. Um câncer é considerado como uma condição grave, e uma morte em decorrência desta doença é esperada, assim como no caso de Aids. Em estudo pioneiro sobre a trajetória do morrer, Glaser e Strauss (1982) afirmam a existência de três tipos de morte rápida: a esperada, na qual fica claro para os profissionais que o paciente morrerá em algumas horas ou, no máximo, em um ou dois dias. A segunda é a morte esperada com a consciência de que o doente irá morrer. A equipe tem certeza de que o doente irá morrer, mas não se antecipa para o pior. Por último, a morte inesperada, quando não se espera que o enfermo morra; espera-se que o paciente se recupere e, ao contrário, ele morre rapidamente, para surpresa dos profissionais e familiares. Em geral, a morte inesperada e a esperada apresentam diferentes impactos, tanto para profissionais como para familiares.

Apesar de seu contato frequente com o processo do morrer, em certas situações alguns intensivistas demonstraram tensão e/ou dificuldade na aceitação da morte. Os enfermos jovens ou com "morte inesperada" provocaram expressão de incômodo, sobretudo ao se tratar de quadro clínico estável e, até, em condições de alta. Neste tipo de situação, alguns profissionais expressaram sentimentos, especialmente aqueles com mais tempo de contato com o doente, como a enfermagem e os fisioterapeutas. Além desses profissionais, por vezes alguns médicos também demonstraram reaçôes.

A equipe médica não permanece rotineiramente ao lado dos pacientes. No início do plantão, os médicos avaliam o quadro clínico, alteram medicações e condutas, e se afastam dos leitos até o fim do turno, na ausência de intercorrências. 
Membros de outras equipes realizam intervençôes diversas vezes ao dia, como retirada da ventilação mecânica dos pacientes em desmame, aspiração traqueal, troca de fraldas, medicações, curativos, banho, mudança de posição, alimentação, entre outras. Essas condutas demandam uma presença constante em contato com o enfermo, uma monitorização contínua, para evitar qualquer desequilíbrio. Os médicos reconhecem que enfermeiros e fisioterapeutas permanecem mais próximos dos doentes:

A enfermagem está mais próxima do doente e por isso podem dizer ao médico se o paciente está urinando ou não (médico).

O contato da fisioterapia e da enfermagem com os pacientes é maior e, por isso, a ligação é maior (médica).

Meerabeau e Page (1998), em estudo baseado em suas experiências clínicas e entrevistas com enfermeiros na enfermaria de cardiologia em Londres, sobre o relato das emoções de enfermeiros após conduta de parada cardiorrespiratória, afirmam que sentimentos de fracasso podem ser expressos, quando os profissionais tendem a superestimar a probabilidade de sucesso na reanimação. Embora a raiva tenha sido expressa em certos momentos, as autoras verificaram que esse sentimento foi particularmente acentuado, ao se tratar de tentativa frustrada de ressuscitação.

Apesar da expressão de sentimentos negativos como a raiva, o riso ocorre com frequência em um evento como parada cardiorrespiratória. Ellis (1991) considera que as emoções são muitas vezes interligadas, ambivalentes ou contraditórias, e diferentes tipos de emoções podem ser sentidas simultaneamente. $\mathrm{O}$ riso pode ser interpretado não como humor, mas como decorrente do sentimento de constrangimento (MEERABEAU; PAGE, 1998).

\section{Morte, gestão das emoções e humor}

Os intensivistas estão em contato constante com a morte, ainda que façam todo o possível para que ela não ocorra. $\mathrm{Na}$ unidade observada, em muitos momentos surgiram brincadeiras entre os profissionais, especialmente ao se tratar de situações tensas, associadas a mortes. Durante um round, ${ }^{17}$ em que um acadêmico de medicina relatava o caso de um doente com câncer, comentou a localização do tumor, concluindo assim sua frase: "saiu do bom para morto". O tumor era de vias biliares, quadro clínico considerado de mau prognóstico. Todos os presentes reagiram com risos. 
Em outra ocasião, a pesquisadora atendeu um telefonema de funcionário da capela do hospital, questionando a presença de familiares de um paciente que havia morrido de madrugada. Contudo, outro doente havia falecido há poucos minutos no setor. Ela perguntou ao médico se poderia avisar ao funcionário da capela para retirar o corpo, e recebeu a seguinte resposta: "a capela está pró-ativa hoje!". Todos riram do comentário.

Brincadeiras surgiram em torno de uma ducha para dar banho no leito: os profissionais apelidaram o objeto de "Michael", em homenagem ao cantor Michael Jackson, pois o aparelho chegou à época em que ele morreu. $\mathrm{Na}$ inauguração da obra da UTI foi comprada outra ducha, desta feita nomeada de "Chorão", pois neste dia ocorreu a morte do cantor.

Esses episódios evidenciam o uso de estratégias pelos intensivistas, em momentos tensos associados à morte. Segundo Menezes (2001, p. 126), o humor é uma forma de expressão e de gestão das emoções neste ambiente. A partir da perspectiva da psicanálise, o humor tem sido compreendido como revelador de verdades - às vezes extremamente difíceis - que só podem vir à tona por meio de chistes ou de metáforas. Como a morte passou a ser encarada na modernidade como fracasso médico, faz-se necessária a construção de modos de gestão, em face deste evento (MENEZES, 2005, p. 212). De acordo com Apte (1985, p. 115), o humor é principalmente verbal, embora muitas vezes seja acompanhado por gestos e outras expressões não verbais. Ele se apresenta em piadas, provérbios, enigmas, rimas, contos, anedotas e lendas. Expressões de profissionais de saúde, como "trambiclínicas", "PIMBA - Pé Inchado Mulambo Bêbado Atropelado", "mulambulatório" são utilizadas como referencial tanto às condições de saúde individuais e coletivas, como às próprias condições de trabalho do profissional de saúde (MENEZES, 2001, p. 128). Segundo Peterson (1998, p. 673), as gírias médicas têm a função de promover harmonia entre profissionais de saúde, manter uma distância entre equipe e pacientes, e reduzir tensões do trabalho médico. $\mathrm{O}$ autor afirma, em estudo sobre gírias médicas cariocas, que elas criam novos significados na relação de médicos, não só com pacientes, mas para sua própria aquisição de conhecimento clínico e experiência, sobretudo para o sistema público de saúde. Deslandes (2004) aponta que a linguagem é um instrumento que reúne diversas dimensões: de gênero, poder, classe social. Essas dimensões refletem uma cultura e constroem as relações e interações no ambiente de saúde (DUARTE; MOREIRA, 2011, p. 690). 
Os intensivistas evitam ao máximo o uso da palavra "morte", ainda que se trate de um evento muito presente na UTI. De acordo com Saloum e Boemer (1999, p. 112), a ausência de verbalização da palavra "morte" denota negação do evento. Brincadeiras, metáforas e eufemismos são frequentemente utilizados por intensivistas, provavelmente para amenizar o sentimento emergente de frustração e impotência em diversas situações, como quando ocorre uma morte "não esperada".

$\mathrm{Na}$ unidade observada, alguns episódios ilustram as reações e expressão, de profissionais, em face de certas situaçôes. Quando um doente com Aids recebeu alta do setor, a equipe esperava que ele vivesse ainda alguns anos. Contudo, quando ele faleceu na enfermaria poucos dias após a alta, o que foi considerado como uma "morte inesperada", que provocou surpresa. Ocorreu então o seguinte diálogo, entre duas fisioterapeutas e o médico da enfermaria:

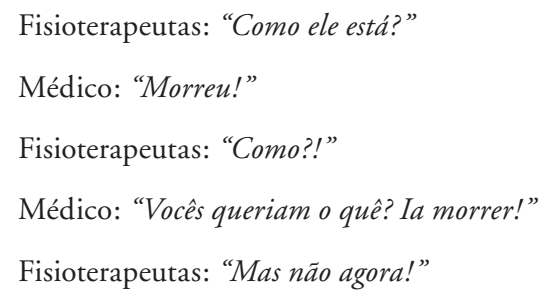

Ao se tratar de paciente "fora de possibilidades terapêuticas de cura" ou de uma "morte esperada", geralmente os comentários são os seguintes: "vai morrer", "esse paciente não sai", "dos oito leitos, nove vão morrer", "ele está com olho de peixe morto, não passará de amanhã", "se piorar, não é para ficar inventando", "não é para ficar nem olhando muito", "tem um prognóstico horrivel, não vou fazer nada para atrapalhar", "pra ficar ruim, precisa melhorar um pouco", "se intubar reza, não sai mais". Essas falas são eufemismos para a morte, o que também foi observado por Menezes (2001, p. 126) em sua pesquisa. Esta maneira de expressão evidencia angústias frente à morte, e o uso de eufemismos pode ser uma estratégia de afastamento do drama, da parte dos intensivistas. Zijderveld (1983) argumenta que humor negro apaga a fronteira entre o culto e o inculto, o próprio e impróprio, o que justifica sua prevalência em situaçōes ambíguas (como o recém-morto), que geram significativo mal-estar entre os que estão presentes. (MEERABEAU; PAGE, 1998, p. 304).

$\mathrm{Na}$ terapia intensiva, o modelo de comportamento dos profissionais indica uma "obrigação" de não expressar sofrimento, para não perturbar a rotina do setor. A maneira adequada de expressão da equipe no setor é o silêncio. Tal 
conduta evidencia o caráter coletivo na expressão social de sentimentos, conforme demonstrado pelo estudo pioneiro de Mauss (1979).

Em seu exercício profissional cotidiano em contato com o sofrimento e com a morte, os intensivistas precisam aprender estratégias de enfrentamento da tensão emocional. Em sua formação profissional, aprendem o autocontrole. A rotina das equipes do hospital é organizada de forma a silenciar a expressão emocional dos profissionais, dos doentes e de seus familiares. A morte tão presente na UTI - é silenciada, regulada e rotinizada, talvez como uma tentativa de banalização desse fenômeno (MENEZES, 2001, p. 126).

\section{Considerações finais}

A UTI é considerada uma "unidade fechada", tanto em seu espaço físico, com janelas e portas fechadas, ar condicionado central, luzes artificiais, mantendo o ambiente externo "lá fora", como pela "superespecialização" de sua equipe profissional, que lida com equipamentos de alta tecnologia para o cuidado de pacientes graves. Por tais características, a equipe intensivista é considerada "melhor" do que a de outros setores do hospital, tanto pelos intensivistas como pelos profissionais de outros setores do hospital.

A rotina do setor é organizada pela equipe, com a função de manter o maior controle possível sobre as condições clínicas e funções vitais do doente, que é mantido em constante monitoramento, por equipamentos eletrônicos, pela equipe de enfermagem. Trata-se de evitar a morte, sempre que possível. Devido às especificidades da unidade, as relações entre a equipe intensivista com os profissionais dos demais setores hospitalares podem ser tensas, pela hierarquia entre os serviços. Dentro do setor, mesmo com a rotina estabelecida em equipe multiprofissional, há forte distinção entre "médicos e demais profissionais de saúde". A palavra e a decisão do médico têm preeminência sobre as demais opiniōes.

Os intensivistas atuam nesse ambiente especializado, com doentes de alta gravidade, de modo que estão em constante contato com a morte. Porém, no setor, o processo do morrer é denominado de diferentes maneiras: como óbito e como parada cardiorrespiratória. Esta diferenciação acarreta formas distintas de ação, assim como de expressão - ou não - de sentimentos. O óbito é entendido como uma morte esperada, quando todos os profissionais aguardavam que aquele enfermo morresse em algumas horas ou em poucos dias. A equipe não faz nada 
para reverter o quadro. Os profissionais não expressam sofrimento quando a morte de fato ocorre. Já na parada cardiorrespiratória, os intensivistas fazem todo o possível para que o paciente sobreviva, utilizam todos os recursos da unidade. Quando o doente sobrevive, há grande satisfação da equipe. Ao contrário, quando a morte ocorre, os profissionais referem a existência de sentimentos de fracasso, insucesso, impotência. Por vezes, eles consideram tratar-se de uma morte inesperada.

A partir dessas definições, é possível diferenciar a visão da "boa morte" na UTI, vista pelos profissionais como aquela em que se deve amenizar o sofrimento do paciente que está morrendo com analgésicos, sedativos e intubações, conectado a aparelhos de ventilação mecânica e monitores, sem a presença dos familiares, apenas dos profissionais, até que o óbito ocorra. Diferente da "boa morte" dos cuidados paliativos, em que nenhum procedimento invasivo é realizado, apenas analgesia, para que o doente não sinta dor e a presença constante da família com o enfermo.

A mobilização de sentimentos na UTI varia de acordo com o doente e com o que acontece com ele. A morte inesperada é uma situação capaz de provocar a emergência de sentimentos, por parte da equipe intensivista. Por vezes, quando o enfermo envolvido é jovem, observa-se o surgimento de desconforto na equipe, pelo fato de aquele indivíduo "ter muita coisa para viver ainda”. No caso de internação prolongada no setor, pode se desenvolver um processo de identificação entre o intensivista e o enfermo, o que pode gerar preocupações com o momento da alta para enfermaria e/ou para casa, se terá ou não os cuidados necessários.

Quando ocorre esse tipo de envolvimento, alguns profissionais utilizam recursos para lidar com a emergência de sentimentos em momentos difíceis, como o uso de eufemismos e de brincadeiras para aliviar o clima tenso. Brincadeiras com uso do nome de artistas que já morreram eram frequentemente utilizadas no setor.

As emoções não são frequentemente demonstradas neste setor. Os profissionais evitam um contato mais próximo com o doente e seus familiares, como modo de evitar envolvimento emocional. Na UTI, a expressão de emoções é considerada uma perturbação à rotina da unidade, que pode atrapalhar a atuação técnica dos profissionais. Por esse motivo, a não expressão se torna uma obrigatoriedade para os intensivistas. Quando não é possível um autocontrole emocional e as emoções afloram, por vezes os profissionais desabafam com os colegas de sua confiança, sejam eles da mesma categoria profissional ou não. ${ }^{18}$ 
APTE, M.L. Humor and laughter: an anthropological approach. London: Cornell University Press, 1985.

ARIÈS, P. História da morte no Ocidente: da Idade Média aos nossos dias. Rio de Janeiro: Nova Fronteira, 2012.

BRASIL. Ministério da Saúde. Secretaria de Vigilância Sanitária. Portaria no 466, de 04 de junho de 1998. Diário Oficial [da] República Federativa do Brasil, 106-E, Brasília, 05 jun. 1998. Disponível em: <http://sna.saude.gov.br/legisla/legisla/uti/>. Acesso em: 20 set. 2012.

COLLINS dicionário prático. São Paulo: Disal, 2001.

DAMATTA, R. O ofício do etnólogo, ou como ter “anthropological blues”. In: NUNES, E. O. (org.). A aventura sociológica. Rio de Janeiro: Jorge Zahar, 1978. p. 23-35.

DESLANDES, S. F. Análise do discurso oficial sobre a humanização da assistência hospitalar. Cienc. Saúde Colet., v. 9, n. 1, p. 7-14, 2004.

DUARTE, M.C.S.; MOREIRA, M.C.N. Autonomia e cuidado em terapia intensiva pediátrica: os paradoxos da prática. Interface: comunicação, saúde, educação. Botucatu, v. 15, n. 38, p. 687-700, 2011.

ELLIS, C. Sociological introspection and emotional experience. Symbolic Interaction, v. 14, n. 1, p. 23-50, 1991.

FOUCAULT, M. Vigiar e punir. Petrópolis: Vozes, 2004.

GLASER, B.G.; STRAUSS, A.L. Patterns of dying. In: BRIM JR., O.G. et al. (eds.). The dying patient. New Jersey: Transaction Books, 1982. p. 129-155.

GLASER, B.; STRAUSS, A. Awareness of dying. Chicago: Aldine, 1965.

GOOD, M.; GOOD, B. Disabling practitioners: hazards of learning to be a doctor in American medical education. American Journal Orthopsychiatry, v. 59, n. 2, p. 302-309, 1989. HERZLICH, C. Os encargos da morte. Rio de Janeiro: IMS-UERJ, 1993.

LOFLAND, L. The craft of dying. Beverley Hills, CA: Sage, 1978.

LUPTON, D. The imperative of health: public health and the regulated body. London: Sage, 1995.

MAUSS, M. A expressão obrigatória de sentimentos. In: OLIVEIRA, R.C. (org.). Marcel Mauss: antropologia. São Paulo: Ática, 1979. p. 147-153.

MEERABEAU, L.; PAGE, S. Getting the job done. In: BENDELOW, G.; WILLIAMS, S. Emotions in social life: critical themes and contemporary issues. London Routledge, 1998. p. 296-312.

MENEZES, R.A. Difíceis decisões: uma abordagem antropológica da prática médica em CTI. Physis: Revista de Saúde Coletiva. Rio de Janeiro, v. 10, n. 2, p. 27-49, 2000. 
Etnografia do ensino médico em um CTI. Interface: comunicação, saúde, educação. Rio de Janeiro, v. 5, n. 9, p. 117-30, 2001.

- Em busca da boa morte: antropologia dos cuidados paliativos. Rio de Janeiro: Garamond: Fiocruz, 2004.

. Profissionais de saúde e a morte: emoções e formas de gestão. Teoria e Sociedade, n. 13, v. 1, p. 200-225, jan.-jun. 2005.

. Difíceis decisóes: etnografia de um centro de tratamento intensivo. Rio de Janeiro:

Fiocruz, 2006.

Trabalho em CTI: ônus e bônus para profissionais de saúde. In: TEIXEIRA, A.C.B.; DADALTO, L. (coord.). Dos hospitais aos tribunais. Belo Horizonte: Del Rey, 2013. p. 413-433.

PETERSEN, A.; WADDELL, C. Health matters: a sociology of illness, prevention and care. Buckingham: Open University Press, 1999.

PETERSON, C. Medical slang in Rio de Janeiro, Brazil. Caderno de Saúde Pública, Rio de Janeiro, v. 14, n. 4, p. 671-699, out.-dez, 1998.

SALOUM, N.H., BOEMER, M.R. A morte no contexto hospitalar: as equipes de reanimação cardíaca. Rev. Latino-am. Enfermagem, Ribeirão Preto, v. 7, n. 5, p. 109-119, dez. 1999.

SEYMOUR, J.E. Critical moments: death and dying in intensive care. Philadelphia, PA: Open University Press, 2001.

SOCIETY OF CRITICAL CARE MEDICINE. Disponível em: <http://www.myicucare. org/Pages/HistoryofCriticalCare.aspx>. Acesso em: 23 set. 2012.

SUDNOW, D. Passing on: the social organization of dying. New Jersey: Prentice-Hall, 1967.

VELHO, G. Observando o familiar. In: NUNES, E. O. (org.). A aventura sociológica. Rio de Janeiro: Zahar, 1978. p. 36-46.

VINCENT, R. Medical ethics, oral communication at resuscitation council of the United Kingdom annual symposium. London, 1991.

ZIJDERVELD, A.C. The sociology of humor and laughter. Current Sociology, v. 31, n. 3, p. 15-33, 1983.

\section{Notas}

${ }^{1}$ A partir daqui, passamos a utilizar a sigla UTI para unidade de tratamento/terapia intensiva, sinônimo de unidade de cuidados intensivos.

${ }^{2}$ http://www.myicucare.org/Pages/HistoryofCriticalCare.aspx. Tradução nossa. Acesso em: 23 set. 2012. 
${ }^{3}$ A ventilação mecânica (ou suporte ventilatório) consiste em um método de suporte para tratamento de pacientes com insuficiência respiratória, pelo uso de aparelhos, denominados ventiladores mecânicos artificiais ou respiradores. Objetiva a manutenção das trocas gasosas e o alívio do trabalho da musculatura respiratória.

${ }^{4}$ http://www.myicucare.org/Pages/HistoryofCriticalCare.aspx. Acesso em: 23 set. 2012.

5 De acordo com RDC No 7, de 24 de fevereiro de 2010, risco refere-se à combinação da probabilidade de ocorrência de um dano e a gravidade de tal dano. Disponível em: <http://brasilsus.com.br/ legislacoes/rdc/102985-7.html>. Acesso em 19 set. 2012.

A definição de risco em saúde pública pode ser separada em duas perspectivas principais: a primeira, vista como um perigo para a saúde das populações que são expostas a riscos ambientais, como poluição, lixo nuclear e resíduos químicos tóxicos. Neste contexto, a ameaça para a saúde é considerada como um risco que é externo, ao longo do qual o indivíduo tem pouco controle. A segunda abordagem concentra-se na consequência das escolhas de vida feitas por indivíduos e, assim, coloca em ênfase o autocontrole. Nesse sentido, é imposto internamente, em função da capacidade do indivíduo para gerir a si mesmo. Um terceiro uso menos comum do termo refere-se a grupos sociais por não terem acesso suficiente aos serviços de saúde. Neste caso, o risco refere-se à desvantagem social, que, dependendo da posição política, pode ser representado como uma função de fatores externos, tal como renda, ou fatores internos, como a falta de motivação, ou uma combinação de ambos. A estratégia de testes de diagnóstico tem sido adotada para lidar com o risco na saúde, tanto externa quanto internamente imposta. A lógica do teste é que os padrões de risco devem ser primeiramente determinados, para identificar aqueles que possuam o potencial para desenvolver determinada condição patológica e, em seguida, tratada. Acredita-se que o exame diagnóstico possa identificar a doença antes dos sintomas aparecerem, o que acarretaria um tempo maior para tratar ou prevenir a doença, ou alertar pessoas para seu potencial de transmissão, tal como o HIV ou de uma doença genética. Possuir um teste, de qualquer tipo, é conceituado como oferecer controle, uma maneira de "fazer alguma coisa" na presença de um potencial de uma doença. A relação entre a definição do risco e da estratégia de testes de diagnóstico é, portanto, sinergética: os indivíduos são estimulados a participar de um teste, pois eles são considerados em risco de desenvolver uma doença ou condição patológica e as estatísticas produzidas servirão para apoiar ou reformular as avaliaçôes dos padrôes de risco na população (LUPTON, 1995, p. 77).

${ }^{6}$ Usamos sempre FPTC em referência a "fora de possibilidades terapêuticas de cura", a partir daqui. Em 1967, Cicely Saunders, assistente social, enfermeira e médica, fundou em Londres a primeira instituição especificamente destinada a proporcionar conforto e amparo aos moribundos: o St. Christopher Hospice, que se transformou em modelo de assistência, ensino e pesquisa no cuidado de pacientes terminais e de suas famílias. Saunders foi pioneira do movimento pelos Cuidados Paliativos. Ela voltou-se à causa da qual se tornaria uma líder: os cuidados dos pacientes em fase avançada de doença. Desde 1960, dedica-se à difusão da ideia de uma nova forma de assistência à fase final da vida. Reivindica a necessidade de desenvolvimento de uma medicina especificamente voltada a uma etapa da vida e da doença - mais adiante denominada como medicina paliativa - centrada no controle da dor e dos sintomas dos doentes FPTC (MENEZES, 2004, p. 53).

${ }^{7}$ Este artigo se baseia no estudo que deu origem a dissertação "Interações em uma Unidade de Terapia Intensiva: um estudo sobre a gestão das emoçôes", realizado em um hospital universitário na cidade do Rio de Janeiro. Não há conflito de interesses. Pesquisa autorizada pelo Comitê de Ética em Pesquisa, Plataforma Brasil, CAAE número 15264313.0.0000.5286. 
${ }^{8}$ Bombas infusoras, um ventilador mecânico, um monitor de sinais vitais preso à parede.

9 Aparelho para a visualização de exames radiográficos (raios-x, tomografias).

${ }^{10}$ A equipe de enfermagem funciona em sistema de plantões: três de dia e três à noite. A maioria dos enfermeiros é do sexo feminino, há dois enfermeiros no plantão noturno. Entre os técnicos, há mais equilíbrio entre homens e mulheres. Na equipe de medicina há 14 médicos, cinco mulheres e nove homens. Já a equipe de fisioterapia conta com oito fisioterapeutas, quatro mulheres e quatro homens.

${ }^{11}$ Especialidade referente ao funcionamento dos rins.

${ }^{12}$ http://www.amib.org.br/conteudo.asp?cod_site=0\&id_menu=53\&men=53. Acesso em: 01 nov. 2013.

${ }_{13}$ Em contato com membros de outras equipes, constata-se que o mesmo ocorre em outras UTIs.

${ }^{14}$ Em estudo etnográfico em centro de tratamento intensivo de hospital público universitário, Menezes (2000, p. 36) constatou a existência de um "sistema" classificatório não oficial, baseado em três eixos. O primeiro funda-se genericamente em uma ordem técnica, avaliável pelo saber médico - eixo de viabilidade. A ele pertencem categorias como "viável" e "inviável", "responsivo", "highlander" e "morredor". O segundo eixo é regido por atributos sociais; indica a posição em contexto social mais amplo e sua inserção na instituição - eixo "social", abarcando categorias como "anônimo", "vip" e "estigmatizado". O terceiro eixo também se funda em características sociais, mas está referido às normas e regras relativas ao comportamento de paciente internado no setor - eixo "institucional". As classificações "cooperativo" e "rebelde" são constituintes desse eixo. Em cada eixo há categorias valoradas positiva e negativamente pelos profissionais: algumas refletem a autoimagem positiva dos intensivistas, enquanto as classificações valoradas negativamente denunciam os limites de sua prática. Ao qualificar um doente de determinada maneira, o profissional inicia inconscientemente um processo decisório. As categorias ordenam simbólica e praticamente a tomada cotidiana de decisões, que constitui o modo mais visível do exercício da prática médica (MENEZES, 2000, p. 37). Esse sistema classificatório é referência central, na escolha e determinação médica pela conduta do "conforto".

${ }^{15}$ DAUDT, F. Condenados à vida. Folha de S. Paulo, São Paulo, 2 abr. 2014. Edição digital. Disponível em: http://wwwl.folha.uol.com.br/fsp/cotidiano/159343-condenados-a-vida.shtml. Acesso em: 2 abr. 2014.

${ }^{16} \mathrm{O}$ caso de uma paciente idosa mobilizou uma enfermeira entrevistada. Sua sedação foi retirada pela equipe médica, e a enfermeira achava que não seria o certo para a doente, pois considerava importante que a paciente "morresse em paz".

17 De acordo com Dicionário Prático Collins (2001, p. 283) round significa rodada, ronda, visitas. No contexto investigado, refere-se a uma reunião de importância central na UTI. As informaçôes dos pacientes são relatadas de forma detalhada - desde a história da internação, evolução, até o exame físico e as dosagens dos medicamentos do dia. Procede-se a uma avaliação e discussão sobre o estado do paciente e as decisões são tomadas: pedidos de exames, pareceres de outros serviços do hospital ou alterações da terapêutica e dos medicamentos (MENEZES, 2000, p. 36).

${ }^{18}$ N.R. da Silva atuou na coleta de dados. N.R. da Silva e R.A. Menezes efetuaram a análise e interpretação dos dados, elaboração, revisão crítica e final do manuscrito. 


\section{"When it's over, it's over": the characterization of death in an intensive care unit in Rio de Janeiro}

The intensive care unit was created to care for seriously ill patients who are at risk of death. For this purpose, it provides uninterrupted medical and nursing care, with specialized human resources and access to sophisticated diagnosis and therapy equipment in order to maintain life. This article presents a reflection around the different possibilities for the dying process in an intensive care unit, based on ethnographic research at a university public hospital in the city of Rio de Janeiro. Despite having frequent contact with the dying process, in certain situations some intensivists demonstrated tension and/or difficulty accepting death, especially in cases of "sudden death". In this type of situation, some professionals expressed feelings, especially those who had been in contact with the patient for a longer period of time. As for "expected death" situations, professionals are expecting the event and are thus less affected by feelings. Since the unit's routine must not be disrupted, strategies are constructed and activated to deal with these situations. This study revealed the use of humor, including euphemisms and jokes, to relieve any tension that may establish itself in the intensive care unit environment, where death is an everyday occurrence.

> Palavras-chave: intensive care; emotions; life/death; death; cardiorespiratory arrest. 